\title{
Riscos e Benefícios da Biópsia Endomiocárdica de Ventrículo Direito
}

\author{
Charles Mady
}

São Paulo, SP

Em todos os congressos que comparecemos, levando nossa experiência em assuntos que utilizam a biópsia endomiocárdica de ventrículo direto (VD) como método, duas questões são levantadas, repetidamente. A primeira, se o método é fiel quanto à amostragem do processo que agride o miocárdio e, a segunda, ao risco do procedimento. Como as colocações têm sido levantadas de forma redundante, resolvemos esclarecer por escrito os fatos referentes a esse assunto.

Em todas as doenças que agridem o miocárdio, é evidente que não encontramos homogeneidade ao longo de toda a musculatura. Como qualquer método de estudo, este também tem seu alcance e procuramos minimizar variações de amostragem, biopsiando o septo do VD em vários pontos, em torno de cinco, para assim obter uma média que, na grande maioria das vezes, representa o miocárdio como um todo. Para confirmar essas observações, basta consultar trabalhos realizados em nosso grupo, mostrando que as alterações morfológicas são tanto mais evidentes quanto pior for a apresentação clínica de determinados tipos de doença ${ }^{1-3}$. Repetindo, não há método de estudo que seja absoluto em suas informações, mas nossos resultados mostram que há alta sensibilidade no procedimento.

Quanto ao risco do procedimento, há alguns fatos que gostaríamos de discutir. Em 1980, defendemos tese de doutoramento na Faculdade de Medicina da USP e o método de estudo era a biópsia endomiocárdica de $\mathrm{VD}^{4}$. Essa tese foi posteriormente publicada em sua íntegra ${ }^{1}$. Na ocasião, um dos mais respeitados patologistas de nossa época, Prof. Dr. Gyorgy Böhm, titular da FMUSP, nos "sabatinou" a respeito do método e, após longa discussão, nos avalizou ética e cientificamente para prosseguirmos em nossa linha de pesquisa. Quais foram as razões que levaram o eminente cientista, que é portador de aguçado espírito crítico, a concordar com a conduta de nosso grupo? As perspectivas terapêuticas que se abririam seriam muito grandes. Para exemplificar, comprovamos em nosso meio, que o tratamento específico da doença de Chagas na forma indeterminada não gerou melhoria do aspecto morfológico dos fragmen-

Instituto do Coração do Hospital das Clínicas - FMUSP

Correspondência: Charles Mady - Incor - Av. Dr. Enéas C. Aguiar, 44 - 05403-000 - São Paulo, SP

Recebido para publicação em 18/11/97

Aceito em 5/1/98 tos de miocárdio obtidos antes e após a terapêutica. ${ }^{5}$ E mais, comprovamos que determinado número de pacientes com cardiomiopatia dilatada "idiopática" tinha, na verdade, miocardite linfocitária ativa, entidade que, na ocasião, recebia tratamento imunossupressor e que uma porcentagem de pacientes com miocardiopatia periparto tinha o mesmo diagnóstico ${ }^{6-7}$. Prosseguindo, a biópsia endomiocárdica é o método padrão para se realizar o diagnóstico de rejeição após a realização do transplante cardíaco, havendo pacientes que realizam dois, três e até quatro procedimentos em um mês. Hoje, temos protocolos de tratamento de miocardiopatias dilatadas e a quantificação de colágeno em fragmentos obtidos pela biópsia pode nos orientar sobre a eficácia da medicação utilizada. Da mesma forma, doenças sistêmicas reumáticas, como a esclerodermia, estão sendo estudadas com a intenção de se observar provável involução do colágeno pós-tratamento específico, como ocorre nos pulmões e na pele.

Portanto, o campo de pesquisa é enorme, com evidentes benefícios terapêuticos para a população em geral. As informações obtidas desses protocolos terão importância muito grande na escolha do tipo de tratamento a se instituir em pacientes miocardiopatas. Hoje em dia, fala-se muito de indicações de tratamento cirúrgico, baseadas em diâmetros e volumes ventriculares, mas, certamente, o que gera os bons e maus resultados é a qualidade da parede desses ventrículos, ou seja, o quanto de músculo e o quanto de colágeno essa parede tem. Essas informações podem ser obtidas pela biópsia endomiocárdica e teremos, dentro dessa linha de pesquisa, indicadores morfológicos de sobrevida, que seriam mais sensíveis que os funcionais, os únicos até hoje utilizados. Do exposto, fica evidente a importância de se conhecer, profundamente, a constituição morfológica, e até bioquímica da parede desses corações. Alguns lembram o aspecto ético da questão. O que seria mais ético, ou anti-ético, se é que podemos empregar esta terminologia desta forma, realizar ventriculectomia desconhecendo a constituição de parede, com mortalidade perioperatória proibitivamente elevada, ou escolher os pacientes com risco menor, após desenvolvermos adequadamente essa linha de pesquisa? Nãoé sem razão que um paciente chagásico tem pior prognóstico que outro com insuficiência aórtica. Este tem o miocárdio menos agredido, com menor deposição de colágeno. Já em 1980, o eminente professor de patologia enxergava, como nós, o quanto esse 
método poderia influenciar, de forma positiva, resultados terapêuticos tanto clínicos como cirúrgicos.

Outra questão, com freqüência levantada nos congressos, é sobre implicações médico-trabalhistas de indivíduos portadores de forma indeterminada da doença de Chagas. Pergunta-se repetidamente se esses indivíduos poderiam desenvolver atividades físicas moderadas ou se poderiam pilotar um avião. E respondemos que sim, para surpresa de alguns. As estimativas oficiais, que subestimam os valores reais, julgam haver ao redor de 3.600.000 indivíduos nessa forma evolutiva da doença. E encontram-se geralmente na faixa etária mais produtiva de suas vidas. E são estigmatizados por serem “doentes", por serem portadores da doença de Chagas. Nossos trabalhos utilizando a biópsia endomiocárdica nesse grupo de indivíduos mostraram que esses corações ou eram normais do ponto de vista morfológico, ou tinham alterações mínimas, não suficientes para gerar disfunções ${ }^{1}$. Por quê, então, deveríamos encarar esses indivíduos como doentes? Será que pilotos de avião, vivendo sob constante estresse, alguns hipertensos ou diabéticos ou com alterações metabólicas, não têm um risco maior do que os portadores de forma indeterminada? Para corroborar nossos pontos de vista, trabalho recente, que foi motivo de tese de doutoramento da Dra Barbara M. Ianni, não mostra evolução para dilatação ventricular em nenhum dos pacientes seguidos a longo prazo. E mais, não houve mortes súbitas ${ }^{8}$. Ou seja, as informações obtidas em 1980 pela biópsia endomiocárdica foram confirmadas. Quanto a sociedade se beneficiou com essas informações?

O método é invasivo, tão invasivo quanto um cateterismo cardíaco e cinecoronariografia, ou a passagem de cateter de Swan-Ganz, ou mesmo biópsias de fígado, rins, pulmões, etc. E o risco do procedimento é muito baixo, mais baixo até que alguns dos métodos mencionados. Basta consultar a experiência de nosso grupo em trabalho recentemente apresentado ${ }^{9}$.

A ética deve gerar uma evolução saudável para a sociedade. Quando estática, pode gerar malefícios. A nossa ética está em primeiro lugar em proporcionar uma melhoria de qualidade e quantidade de vida de nossos pacientes. Se um determinado método abre a perspectiva dessa melhoria, não temos eticamente o direito de negá-lo.

Procuramos, com este breve relato, deixar patente nossos pontos de vista em relação ao método em questão.

\section{Referências}

1. Mady C, Pereira-Barretto AC, Ianni BM, Lopes EA, Pileggi F - Right ventricular endomyocardial biopsy in undetermined form of Chagas' disease. Angiology 1984; 35: 755-9.

2. Pereira-Barretto AC, Mady C, Arteaga-Fernández E et al - Right ventricular endomyocardial biopsy in chronic Chagas' disease. Am Heart J 1986; 111:307-12.

3. Mady C, Saldiva PHN, Caldini EG et al - Interstitial myocardial fibrosis is significantly associated with the degree of functional impairment in Chagas' cardiomyopathy. Joint XII ${ }^{\text {th }}$ World Congress of Cardiology and XVI ${ }^{\text {th }}$ Congress of the European Society of Cardiology. Berlin-Alemanha, 1994; Anais: 590.

4. Mady C-Biópsia endomiocárdica do ventrículo direito na forma indeterminada da doença de Chagas (tese de doutoramento). São Paulo: Faculdade de Medicina da USP, 1980

5. Ianni BM, Arteaga E, Mady C, Pereira Barretto AC, Luz PL, Pileggi F - Uso do benzonidazol em chagásicos na forma indeterminada. Resultados a longo prazo. Congresso Paulista de Cardiologia, III. Campos do Jordão, SP, 1992 (anais).

6. Mady C, Pereira-Barretto AC, Bellotti G et al - Infiltrado linfocitário ativo na miocardiopatia dilatada idiopática. Arq Bras Cardiol 1986;47(3):243-246.

7. Mady C, Pereira-Barretto AC, Bellotti G et al - Biópsia endomiocárdica em pacientes portadoras de miocardiopatia periparto. Arq Bras Cardiol 1986; 47: 403-5.

8. Ianni BM - Forma indeterminadea da doença de Chagas. Avaliação evolutiva de parâmetros clínicos, eletrocardiográficos e ecocardiográficos. São Paulo: Faculdade de Medicina da USP, 1995.

9 Fiorelli AI, Stolf NAG, Moreira LFP, Bacal F, Igushi L, Jatene AD - Bióspia endomiocárdica de ventrículo diteito - Experiência de 3433 casos. Arq Bras Cardiol 1997; 69: 71. 